\title{
Unable to Find a Research Title?
}

\author{
- Bal Mukunda Bhandari
}

\begin{abstract}
Most of the Master's students who opt for thesis writing could not find an appropriate title for them, and they ask their supervisors, professors and seniors for a title. Similarly those who are aspiring for a Ph.D. cannot start the work because they are unable to find a suitable title for them. When I ask my colleagues and students to go for Ph.D., to carry out classroom research and other small scale research, to write research article, they say that they have no idea on what to write, and they ask me to provide them with a topic for the research. This article, based on my experience of supervising and evaluating theses, is an attempt to help Master's and Ph.D. students in general and M.Ed. English students in particular, find a suitable title for their research. It discusses some sources, from which thesis titles come, viz. problem, curiosity, disagreement, courses of study, and previous works in the related field.
\end{abstract}

Key words: Research, research titles, problems, curiosity, disagreement.

\section{Getting started}

People have different feelings about the term 'research' which comes from old French recerchier and middle French recherché meaning to go about seeking. Some people feel it highsounding while others feel it laborious. Some people think, it is not within the reach of them and are afraid of it while others love it. Research, as Merriam Webster's Collegiate Dictionary defines, is a careful and diligent search. It is the investigation or experimentation aimed at the discovery and interpretation of facts. It can also be carried out for revision of accepted theories or laws in the light of new facts. A piece of research may be carried out to receive a degree from a university or to develop profession or to solve some practical problems.
Most of the students who are doing their Master's degree or those who want to enroll into $\mathrm{Ph}$.D. get stuck on the first step. They are unable to select an appropriate title for them because "searching a title for thesis is seldom a simple matter even after you discover a title that attracts your interest, you may well find yourself revisiting your choice, modifying your approach, or changing title altogether after you have begun research" (Gibaldi, 2000, p.4). You can use one of the models of research. It may be survey, an experiment, a case study or an action research, and you can choose qualitative or quantitative design depending upon the nature of the issue, your knowledge, resources and enthusiasm. Only after a research topic has been chosen and finalized, you can decide what data would be 
relevant to its investigation and how such data can best be obtained. When you choose a topic for your research, you should consider whether it is feasible in terms of time, resources, access and your technical abilities.

\section{Sources of research titles}

Finding an interesting and feasible topic that suits you is not straightforward and one go process because good ideas originate blending of theories, experiences and prior findings. Some of the practical ways of selecting of a topic for an academic research (Master's or Ph. D.) are discussed in the following points:

\section{Research titles come from problems}

A problem might be a situation or an issue that might be one from your own job-related experience or from reading scholarly or professional literature (Daymon \& Holloway, 2002). As a student or a teacher you may have faced many problems and you may have tried to escape from them. Very often you may have become frustrated from your work. Now it's time to realize that problems can be your resources.

Problem 1: In a workshop that was organized for Higher Secondary Level English teachers where I distributed an answer copy (which I had made many by means of Xerox) of class twelve to 32 teachers for marking. When I saw the marking, it was surprising. Out of 100 , the marks varied from 26 to 52 (Bhandari, 2005). Such a great difference! The same copy was marked differently. This is the reason our students often complain about the marks they get. If this case is interesting to you, you can write your thesis in this area. You may try to find out how the gap could be minimized.
Problem 2:We often hear complaints about our teachers' performance though most of them are trained. Teachers are trained but their performance is poor! Why? Now you can carry out your research to find out what is lacking in our teacher training. Where is the problem? In policy? Incourse? In teacher education? Materials? In delivery mechanism? In the trainees? Or, where? You can also compare teacher education system between Nepal and other country/ies.

Problem 3: An M.Ed. student of mine who was also a teacher once went to test speaking skill of SLC students. He asked questions like, where are you from?, (Showing a picture of a bird) what is this? (Showing a picture of a bird over a tree) where is the bird?. He asked pairs of students to talk about their family members and activities like this. Most of the students did not answer his questions. No pair could do the dialogue. The students who were good in the class and those who had done well in the written exam also could not answer his questions.

This might be the problem of your students too. This is the situation that the students are afraid of oral exam and they were nervous. This can be improved by conducting lots of communicative activities in the class. The title of your thesis could be "Developing oral skill through communicative activities".

Problem 4: Every year you have been teaching different aspects of grammar. You taught prepositions and conjunctions, tense and agreement, voice and narration, conditional sentences and relative clauses and everything of English grammar. The students when they are at sentence level they can answer correctly, but when they write or speak longer texts at 
discourse level, it seems that they have not studied any grammar.

This is a common problem with most of our students. This is because they were not taught practically. They did not practice at discourse level. They were not exposed to 'real' English. So, you can carry out your research on this problem. Thus, your title will be 'Teaching grammar at discourse level'.

\section{Research titles come from curiosity}

A curious mind comes up with an invention. If you are curious, your curiosity can be a source of your research. The research process indeed is about solving a curiosity or a mystery. While doing so you may come up with questions: (i) How or why did $\mathrm{x}$ develop? (ii) How does $\mathrm{x}$ work? (iii) What influence does $\mathrm{x}$ have on $\mathrm{y}$ ? (Silverman, 2000 cited in Daymon \& Halloway, 2007, p. 24).

Curiosity 1: Nowadays many of the government aided schools have started launching English medium instruction. Your curiosity could beWhat is the effect of English medium instruction in learning English? Or others? Similarly institutions, colleges, and schools are mushrooming. This may arouse curiosity in you and provide you with the research topics.

Curiosity 2: All the students in a particular class get same exposure. Same teachers teach them; same question paper is given to them; same way of marking is followed, yet the students obtain different marks. Sometimes among the students of similar talent some get higher marks while others get lower marks. If you are curious to know why this is so, then you are interested in studying strategies and examination behavior of the students. Such as, how they prepare for the exams; how they organize their answers, etc.
Curiosity 3: In addition to mainstream schooling, we have Gumba, Madrasa, Gurukul and Adult learners' schools. You may be interested to know the education system of these institutions.

Curiosity 4: When you studied English morphology, you found suffixes and prefixes in English, so is the case with Nepali, but we also find infixes in Newari. You are curious to know how infixes are used in Newari. So your title can be 'Affixation in Newari and English.' Other similar titles can be pluralization in Nepali and English, tense aspect in Gurung and English, relativization in Maithili and English, concord in Nepali and English. There are so many of such titles.

The followings are the areas of curiosity in which research works can be carried out in the Department of English Language Education.

1. Error Analysis

2. Proficiency

3. Methods of Teaching

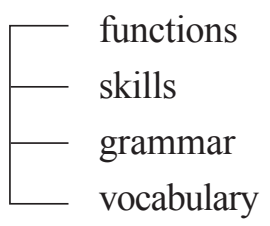

4. Instructional Materials

5. Medium of Instruction

6. Listening Skill

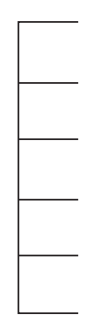
teaching techniques teaching materials learning strategies proficiency error analysis classroom-activities

7. Speaking Skill

8. Reading Skill

9. Writing Skill

10. Teaching of grammar 
11. Vocabulary

12. Spelling

13. Language functions

14. Teaching of English Literature

15. Contrastive/ Comparative Study

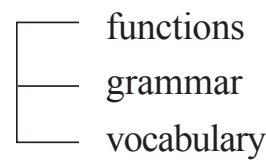

- construction of test

- marking scheme

16. Testing and - washback effect evaluation - correction technique - current trends of evaluation L evaluation

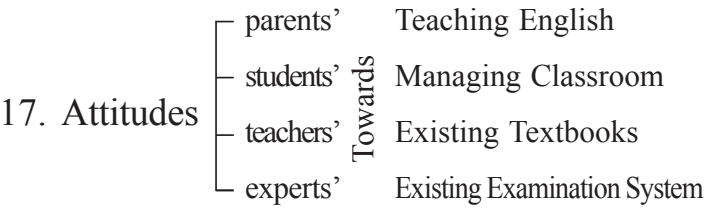

18. Translation $\begin{array}{ll} & \text { news } \\ & \text { literary genre } \\ \text { textbooks songs }\end{array}$

19. Teachers' Guide — correlation with textbook - practice, difficulty availability

20. Language Training<smiles>C1=CC2CCC12</smiles>
duration implementation attitudes problems in implementation

21. Language used in electronic devices

- business correspondence
- chat, SMS, mail
advertisement

22. Behaviour — teachers'

23. Mass media
24. Textbook Analysis

25. Language Planning

26. English for specific purpose/Register

27. Motivation

28. Computer Assisted Language Learning

29. First/Second Language Acquisition

30. Discourse analysis

31. Semantics and Pragmatics

This list of the general area is not the final one. Many more new areas related to applied linguistics and particularly ELT can be added to your curiosity.

\section{Research titles come from dissatisfaction/disagreement}

You may come across many things which you cannot agree, and you were not satisfied with the explanations. If so, they can be the sources of your thesis titles.

Disagreement 1: The government has encouraged inter-cast marriage, but you do not agree with this decision. So, your disagreement will be a source of the topic of research.

Disagreement 2: Your municipality is going to construct a house for old people, but you are not satisfied with this decision with the view that keeping old people away from their home makes new generation irresponsible to their parents. In this case I suggest you to carry out a piece of research in this area.

Disagreement 3: During your Master's, you were taught that students can learn better/more if they are exposed to 'real' language. But you think that explicit and structured teaching will help them learn better/more. So my suggestion is 'do not debate, conduct a research'. You teach structured writing, rules, principles, formats in one group, 
but supply plenty of examples in another group. Similarly, you teach grammar to one group, while other group is exposed to spoken and written English, to one group you teach sound system whereas other group is simply exposed to native speech by a person in the class or cassettes/CDs or a language teaching program.

\section{Conclusion}

In this paper I have discussed some sources of research titles. All of these sources are interconnected. If you pull the thread of one, you will pull all of them. You studied many courses during your study and you have been teaching many courses. Research titles are hidden in each of the courses. If you look at with a researcher's eye, you will find a lot of research topics. Similarly, previous studies, theses and research articles can be of great help to find a research topic. You can also get ideas from your seniors, scholars, experts and supervisors about what to carry out a research project or about what to write on. My suggestion to you is to follow what I have put forward in this article. I think it is the will that helps you find an appropriate title for your research.

\section{About the author}

Dr. Bhandari is Associate Professor of English Education at Central Department of Education, Faculty of Education, TU. Recently, he is the Executive Director of the Centre for International Relations, Tribhuvan University Kathmandu, Nepal. He has authored many textbooks and references beside dozens of research and academic articles in national and international journals on different aspects, and subjects of ELT. His interest lies on lexicography, editing, materials writing, teaching, and teacher training.

\section{References}

American Psychological Association. (2006). Publication mannual of the American Psychological Association (sixth edition). Washington, DC: American Psychological Association.

Best, J. W., \& Kahn, J. V. (2003). Research in education. New Delhi: Prentice Hall of India.

Bhandari, B.M. (2005). Testing: A question of reliability. In Journal of NELTA. Vol. 10. Kathmandu: Nepal English Language Teachers' Association, pp. 20-23.

Cohen, L., Manion, L., \& Morrison, K. (2007). Research methods in education. London: Routledge.

Daymon, C., \& Holloway, I. (2002). Qualitative research methods in public relations and marketing communications. London: Routledge.

Gibaldi, J. (2001). MLA handbook for writers of research papers. New Delhi: Affiliated East-West Press Pvt. Ltd.

Kothari, C. R. (2004). Research methodology. New Delhi: New Sage International Publishers.

Kumar, R. (1999). Research methodology. London: Sage Publication

Nunan, D. (1993). Research methods in language learning. Cambridge: Cambridge University Press.

Paltridge, B., \& Starfield, S. (2007). Thesis and dissertation writing in a second language. London: Routledge.

Somekh, B. (2006). Action research. Berkshire: Open University Press.

Walliman, N. (2001). Your research project. London: Sage Publication.

This article is a modified version of my paper presented in the seminar organized by the Research Division, TU. 